06

\title{
Внутреннее трение стеклоуглепластиков с матрицей Т-107
}

\author{
( Ю.Е. Калинин, А.Т. Косилов, О.В. Овдак, А.М. Кудрин, О.А. Караева, М.А. Каширин, Д.Я. Дегтярёв
}

Воронежский государственный технический университет, 394026 Воронеж, Россия

e-mail: kalinin48@mail.ru

(Поступило в Редакцию 1 июня 2018 г.)

Представлены результаты исследования температурных и амплитудных зависимостей внутреннего трения гибридных композитов из углеродных однонаправленных волокон и стеклянных тканей в эпоксидной расплавной матрице Т-107. По высокотемпературному участку фона внутреннего трения с учетом низкотемпературного участка фона была сделана оценка энергии миграции и образования вакансиоподобного дефекта аморфной матрицы исследуемых стелоуглепластиков.

DOI: $10.21883 /$ JTF.2019.04.47316.217-18

\section{Введение}

В последние годы в авиационной, космической и ракетной отраслях промышленности наблюдается замена многих металлических конструкций на изделия из полимерных композиционных материалов (ПКМ). При этом увеличивается не только спрос и ассортимент ПКМ, но и возрастают требования как к физико-механическим параметрам материала, так и методам их исследования и контроля [1,2]. Наиболее широкое применение во многих отраслях промышленности находят стекло- и углепластики, обладающие высокой механической прочностью, стойкостью к воздействию агрессивных сред в различных условиях эксплуатации, разнообразием и простотой технологических методов изготовления изделий и др. $[3,4]$.

Особое место среди методов исследования ПКМ занимает метод внутреннего трения, применение которого важно с научной и практической точек зрения. С научной точки зрения применение метода внутреннего трения дает возможность получить ценную информацию для развития современных представлений о физических процессах в твердых телах [5,6]. С другой стороны, проблема защиты от вибраций и шумов, которая является актуальной для многих сфер деятельности человека (начиная от производства спортивного инвентаря, обуви и ручного инструмента до изделий автомобильной и авиационной отраслей) может быть решена, если сам конструкционный материал обладает хорошими демпфирующими свойствами $[7,8]$.

С учетом вышесказанного целью настоящей работы было исследование температурной и амплитудной зависимостей внутреннего трения гибридного ПКМ на основе угле- и стекловолокон с разным процентным соотношением в матрице расплавного эпоксидного связующего марки Т-107, состав которого разработан химическим факультетом МГУ им. М.В. Ломоносова [9].

В настоящей работе в качестве основного армирующего наполнителя использовалась однонаправленная лента с углеродным волокном Formosa TC-35 (12 K)
$\left(\sigma_{B}=4000 \mathrm{MPa}, E=240 \mathrm{GPa}\right)[10]$. В качестве материала, предназначенного полностью или частично заменить углеродный наполнитель в ПКМ, использовали стеклоткань марки Т-10-14 [11]. Препреги (полуфабрикаты) на основе угле- и стекло-наполнителей были получены методом Hot-melt на основе расплавного эпоксидного связующего Т-107 с помощью лабораторного технологического комплекса пропитки COS.T.A. по методике, описанной в [12]. Характеристики исходных материалов представлены в табл. 1.

Препрег получали из расчета наноса связующего 36-40\% от массы готового полуфабриката. В итоге были получены следующие препреги:

- углеродная однонаправленная лента на основе нитей Formosa TC-35 (12 K) + полимерное эпоксидное связующее Т-107 с поверхностной плотностью готового полуфабриката $-343-367 \mathrm{~g} / \mathrm{m}^{2}$;

- стеклоткань Т-10-14 + полимерное эпоксидное связующее Т-107 с поверхностной плотностью готового препрега - 454-483 g/m².

После получения препрегов производили раскрой и выкладку слоев полуфабрикатов, а затем сборку технологических пакетов для формования пластин ПКМ методом прямого прессования с использованием прессов Langzaunerperfect LZT-UK-25-L. Для получения пластин раскрой и выкладку слоев производили в направлении $0^{\circ}$, а укладку производили в различной последовательности слоев симметрично относительно середины образца для получения необходимого состава и количества армирующего компонента.

Объемные доли компонентов в гибридном пластике представлены в табл. 2. Из полученных пластин с помощью высокоточного отрезного станка DeWalt были вырезаны элементарные образцы квадратной формы размером $1 \times 1 \times 100 \mathrm{~mm}$ для проведения измерений.

Измерение внутреннего трения проводили методом свободно-затухающих крутильных колебаний на обратном маятнике в воздушной атмосфере [13]. Расчет относительной амплитуды деформации производили по 
Таблица 1. Характеристики исходных материалов

\begin{tabular}{c|c|c|c}
\hline Вид материала & Наименование & $\begin{array}{c}\text { Предел прочности } \\
\text { (не менее), MРa }\end{array}$ & $\begin{array}{c}\text { Модуль упругости } \\
(\text { не менее), GPa }\end{array}$ \\
\hline $\begin{array}{c}\text { Армирующий } \\
\text { наполнитель 1 }\end{array}$ & $\begin{array}{c}\text { Углеродная } \\
\text { однонаправленная лента } \\
\text { на основе Formosa TC-35 } \\
(12 \mathrm{~K})\end{array}$ & 1900 & 100 \\
\hline $\begin{array}{c}\text { Армирующий } \\
\text { наполнитель 2 }\end{array}$ & Стеклоткань Т-10-14 & 500 & 25 \\
\hline $\begin{array}{c}\text { Полимерная } \\
\text { эпоксидная } \\
\text { матрица }\end{array}$ & Т-107 & 91 & -
\end{tabular}

Таблица 2. Объемные доли компонентов в гибридном пластике

\begin{tabular}{c|c|c|c|c}
\hline Материал & $V$ пластика, $\mathrm{cm}^{3}$ & $V$ доля $(\mathrm{Y})$ & $V$ доля $(\mathrm{C})$ & $V$ доля $(\mathrm{M})$ \\
\hline $\mathrm{Y}$ & 81.18 & 67.92 & 0.00 & 32.08 \\
$\mathrm{C}$ & 96.75 & 0.00 & 55.85 & 44.15 \\
$\mathrm{Y}+\mathrm{C}$ & 83.82 & 36.91 & 25.08 & 38.01 \\
$\mathrm{У}+\mathrm{C}$ & 85.14 & 2.87 & 41.08 & 32.06 \\
$\mathrm{У}+\mathrm{C}$ & 81.84 & 47.66 & 19.70 & 32.63
\end{tabular}

выражению

$$
\varepsilon=\frac{r}{\varphi} \lambda,
$$

где $r$ - радиус образца, $\lambda$ - длина образца, $\varphi-$ угол поворота при крутильных колебаниях, который рассчитывают как отношение амплитуды светового зайчика на шкале к расстоянию от крутильного маятника до шкалы. Внутреннее трение рассчитывали по формуле

$$
Q^{-1}=\frac{1}{\pi n} \ln \frac{\varepsilon_{1}}{\varepsilon_{n+1}} .
$$

\section{Результаты эксперимента}

На рис. 1 представлены температурные зависимости внутреннего трения стеклоуглепластиков в матрице Т-107 с различным содержанием углеродных и стеклянных волокон. При комнатной температуре величина внутреннего трения практически не отличается и составляет $Q^{-1} \sim 5 \cdot 10^{-3}$. Повышение температуры до $T \sim 450 \mathrm{~K}$ сопровождается незначительным ростом, который сменяется экспоненциальным ростом внутреннего трения. При приближении температуры к температуре стеклования $(T=458 \mathrm{~K})$ величина внутреннего трения еще больше возрастает. Из графика видно, что при температурах, выше температуры $T \sim 450 \mathrm{~K}$, происходит более резкий рост величины внутреннего трения.

На рис. 2 представлены амплитудные зависимости внутреннего трения для стеклопластика, углепластика и стеклоуглепластиков в матрице Т-107 при комнатной температуре. Величина внутреннего трения с увели-

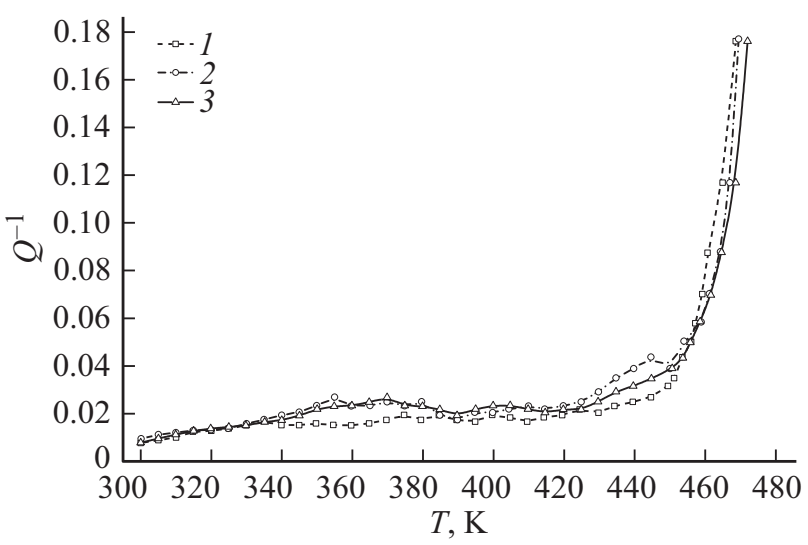

Рис. 1. Температурная зависимость внутреннего трения для стеклопластика (1), углепластика (2) и стеклоуглепластика (3) в матрице Т-107.

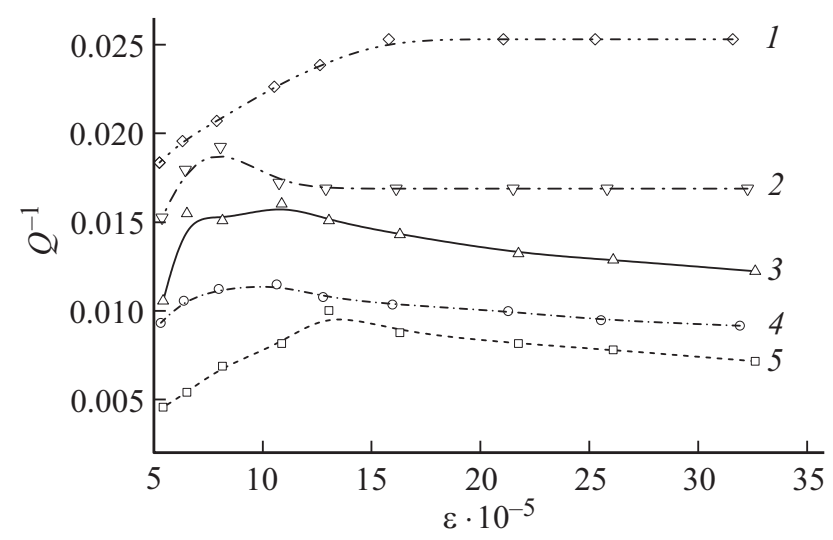

Рис. 2. Амплитудные зависимости внутреннего трения для стеклопластика, углепластика и стеклоуглепластиков в матрице Т-107 с различными наполнителями: 1 - стеклопластика Т-10-14 (100\%); 2 - стеклопластика Т-10-14 (70\%) и углепластика FormosaTC-35 (12 K) (30\%; 3 - стеклопластика T-10-14 $(50 \%)$ и углепластика FormosaTC-35 (12 K) $(50 \%) ; 4$ - стеклопластика T-10-14 (30\%) и углепластика FormosaTC-35 (12 K) $(70 \%) ; 5$ - из углепластика FormosaTC-35 (12 K) (100\%). 
чением амплитуды механических колебаний для всех образцов вначале растет, а затем выходит на насыщение. Однако с увеличением содержания стеклянного наполнителя и уменьшения углеродного волокна общий фон внутреннего трения растет при всех исследуемых амплитудах механических колебаний. Полученные результаты качественно совпадают с результатами исследований внутреннего трения в полимерных композитах, армированных волокнами, с другой матрицей [14].

\section{Обсуждение полученных результатов}

Наблюдаемые экспериментальные результаты по температурной зависимости внутреннего трения при температурах, близких к температуре стеклования, показывают, что внутреннее трение заметно возрастает и этот рост связан с полимерной матрицей, а не с материалом наполнителя. Такой рост обычно называют высокотемпературным фоном внутреннего трения и он описывается экспоненциальной зависимостью от обратной температуры [5]. Для того чтобы установить характер зависимости внутреннего трения в этой области температур, перестроим исследуемые зависимости в координатах $\ln Q^{-1}-f(1 / T)$ На рис. 3 представлена зависимость натурального логарифма внутреннего трения от обратной температуры для стеклоуглепластика, углепластика и стеклопластика с матрицей Т-107. Как видно из рис. 3, в области высокотемпературного фона на зависимостях $\ln Q^{-1} \sim(1 / T)$ наблюдаются два прямолинейных участка (до температуры стеклования и после температуры стеклования).

Тот факт, что температурная зависимость внутреннего трения в исследуемых стеклоуглепластиках не зависит от концентрации наполнителя, свидетельствует об определяющем влиянии матрицы на исследуемую характеристику. Введение же углеродных и стеклянных волокон в полимерную матрицу позволяет снизить общий фон

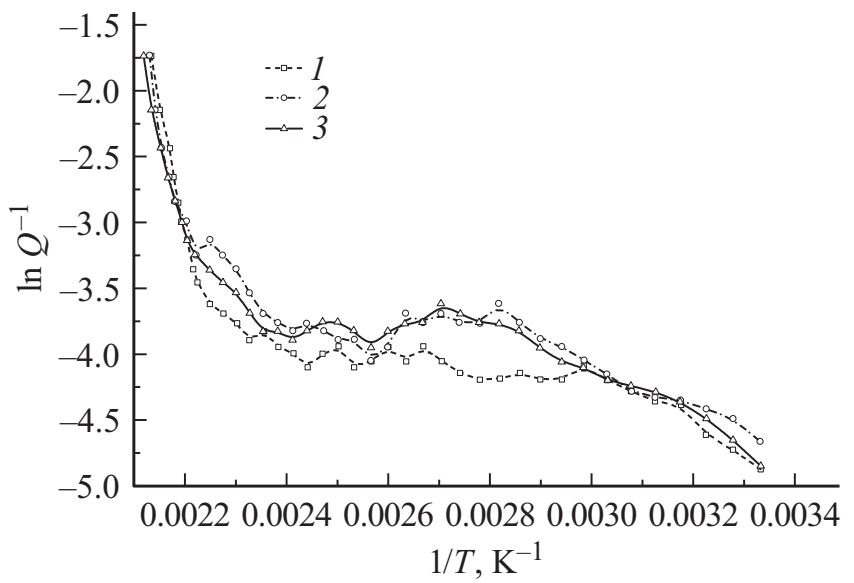

Pис. 3. Зависимость натурального логарифма внутреннего трения от обратной температуры для стеклопластика, углепластика и стеклоуглепластика с матрицей Т-107.

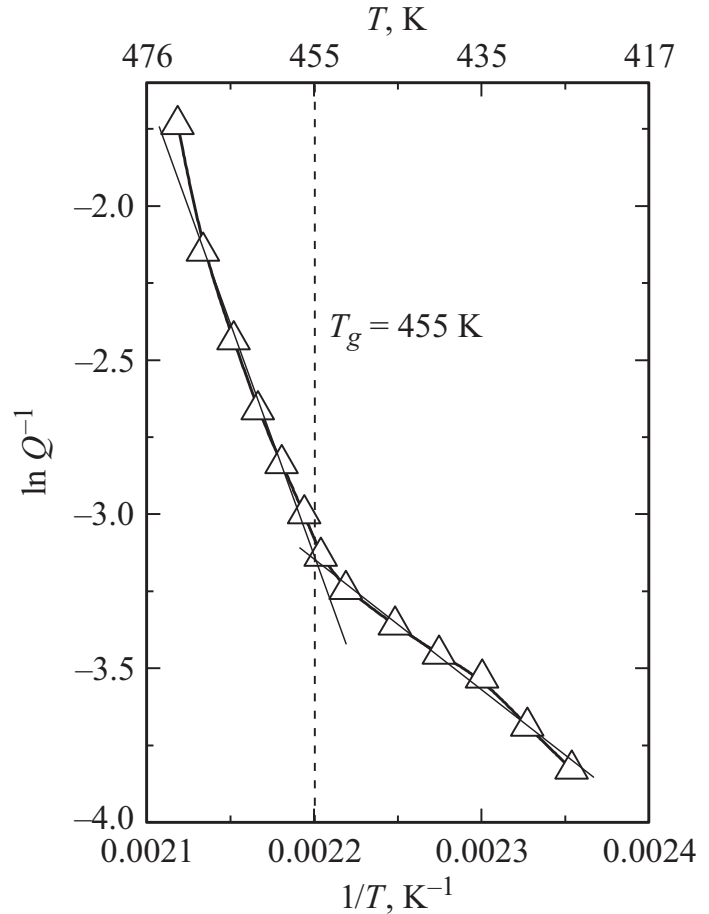

Pис. 4. Участок высокотемпературного фона графика зависимости натурального логарифма внутреннего трения от обратной температуры для стеклопластика с матрицей Т-107.

внутреннего трения и измерить его до более высоких температур.

Наибольший интерес представляет высокотемпературный участок графика, изображенный на рис. 4. По температуре пересечения прямолинейных участков экспоненциального роста внутреннего трения была определена температура стеклования полимерной матрицы, которая оказалась равной $T \sim 455 \mathrm{~K}$, что в пределах погрешности совпадает с табличными данными для матрицы композита [11].

Для аморфной полимерной матрицы высокотемпературный фон внутреннего трения можно связать с миграцией оборванных химических связей аморфной структуры полимерной матрицы. Причем высокотемпературный участок фона внутреннего трения (после температуры стеклования) связывается с миграцией равновесных точечных дефектов аморфной матрицы, а низкотемпературный участок фона внутреннего трения (до температуры стеклования) - неравновесных. Величину внутреннего трения в этом случае можно описать с помощью следующих формул [15]:

$$
\begin{gathered}
Q^{-1}=Q_{0}^{-1} \times \exp \left(\frac{E_{m}}{2 k T}\right), \\
Q^{-1}=Q_{0}^{-1} \times \exp \left(\frac{E_{m / 2}+E_{v}}{k T}\right),
\end{gathered}
$$

где $E_{m}-$ энергия активации подвижного дефекта, $E_{v}-$ энергия образования дефектов, $k-$ постоянная Больцмана, $T$ - абсолютная температура. 
Следовательно, аппроксимируя полученные зависимости внутреннего трения до температуры стеклования, можно оценить энергию активации миграции дефектов для матрицы исследуемого композита по тангенсу угла наклона зависимости $\ln Q^{-1} \sim(1 / T)$. Учитывая, что в этом интервале температур внутреннее трение может быть описано уравнением (3), по экспериментальной зависимости $\ln Q^{-1} \sim(1 / T)$ (рис. 4) можно оценить значение энергии акт миграции точечного дефекта матрицы, которая оказалась равной $E_{m}=0.70 \pm 0.05 \mathrm{eV}$.

По высокотемпературному участку фона внутреннего трения с учетом низкотемпературного участка фона можно оценить энергию образования вакансиоподобного дефекта аморфной матрицы исследуемых стелоуглепластиков. Для этого из энергии активации высокотемпературного участка фона внутреннего трения $E=1.01 \pm 0.05 \mathrm{eV}$ вычтем значение $E_{m} / 2=0.35 \pm 0.05 \mathrm{eV}$ и получим величину, равную $E_{v}=0.66 \pm 0.05 \mathrm{eV}$. Полученное значение в пределах погрешности совпадает со значением энергии миграции. Если предположить, что процесс миграции вакансиоподобных дефектов связан с переключением оборванных химических связей аморфной матрицы, а образование с термической активацией новых оборванных химических связей, то равенство энергии миграции и образования будет вполне закономерным явлением.

Таким образом, полученные значения энергий миграции и образования вакансиоподобных дефектов аморфной матрицы имеют разумную величину и соответствуют энергии связи между двумя соседними наиболее слабо связанными атомами полимерной матрицы.

Анализ амплитудных зависимостей внутреннего трения показал, что зависимость величины внутреннего трения с ростом амплитуды колебаний носит сложный немонотонный характер. Для всех образцов независимо от состава при малых амплитудах наблюдается подъем уровня потерь, который сменяется последующим монотонным снижением, либо выходом на постоянный уровень. Для полимерной матрицы без наполнителя характерно нарастающее падение уровня потерь с ростом амплитуды колебаний.

Немонотонный характер поведения амплитудной зависимости внутреннего трения свидетельствует о том, что неупругая составляющая деформации от амплитуды колебаний носит сугубо нелинейный характер, а наблюдаемое отставание потерь от упругой составляющей при больших амплитудах очевидно связано со спецификой структуры и упругопластических свойств композита. Это относится, прежде всего, к полимерной матрице, в которой реализуются очаги неупругих перестроечных процессов.

Если в структуре полимера имеется множество локальных центров химических связей, образующих двухьямные модели, в которых атомы под действием внешней нагрузки переходят в новые метастабильные состояния и вновь возвращаются в исходные позиции после снятия нагрузки, то величину внутреннего трения можно оценить по формуле

$$
Q^{-1}=\frac{1}{2 \pi} \frac{\Delta W}{W}=\frac{1}{2 \pi} \frac{\int_{0}^{\sigma_{0}} v_{0} \varepsilon_{0} \sigma \rho(\sigma) d \sigma}{\sigma_{0 \mathrm{eff}}^{2} / 2 \mu_{\mathrm{eff}}},
$$

где $v_{0}$ и $\varepsilon_{0}-$ средняя величина объема локального центра в полимерной матрице и величина неупругой деформации, реализованная в каждом из этих центров соответственно; $\rho(\sigma)$ - плотность неупругих локальных центров, отнесенная к единичному интервалу приложенного в текущий момент времени напряжения; $\sigma$, $\sigma_{0}$ - амплитуда периодического напряжения в объеме полимера; $\sigma_{0 \text { eff }}$ и $\mu_{\text {eff }}$ - эффективные величины амплитуды напряжения и модуля сдвига композита с учетом полимерной матрицы и наполнителя.

Плотность локальных центров $\rho(\sigma)$, входящая в выражение для величины потерь за период колебаний $\Delta W$, определяет поведение амплитудной зависимости внутреннего трения. Так, если предположить, что плотность локальных центров $\rho(\sigma)=\rho_{0}$ не зависит от $\sigma$, то выражение для $Q^{-1}$ принимает вид

$$
Q^{-1}=\frac{1}{2 \pi} \frac{\Delta W}{W}=\frac{1}{4 \pi} \frac{v_{0} \varepsilon_{0} \sigma_{0}^{2} \rho_{0}}{\left(\sigma_{0 \mathrm{eff}}^{2} / 2 \mu_{\mathrm{eff}}\right)} .
$$

Так как $\sigma_{0}$ и $\sigma_{0 \mathrm{eff}}^{2}$ связаны между собой линейной зависимостью, то, согласно (6), внутреннее трение в этом случае оказывается амплитудно независимым. Аналогично можно показать, что если с ростом $\sigma$ плотность локальных центров $\rho(\sigma)$ уменьшается как $\sigma^{-1}$, то и $Q^{-1}$ при этом уменьшается как $\sigma_{0}^{-1}$. Таким образом, исходя из предложенной модели, внутреннее трение с ростом амплитуды приложенной нагрузки повторяет уровень спектральной плотности стартовых напряжений полимерной матрицы. В соответствие с рис. 2 резкий рост при малых амплитудах и дальнейшее понижение потерь при больших амплитудах, согласно представленной модели, отражает поведение плотности локальных центров от уровня напряжения.

Смещение кривых амплитудной зависимости в область более высоких потерь по мере роста объемной доли стекловолокна и уменьшения объемной доли углеродных волокон, по-видимому, связано с уменьшением величины накопленной за период колебаний упругой энергии $W=\sigma_{0 \text { eff }}^{2} / 2 \mu_{\text {eff }}$ при неизменной величине амплитуды переменной деформации.

\section{Заключение}

Исследованы температурные зависимости внутреннего трения гибридных композитов из углеродных однонаправленных волокон и стеклянных тканей в эпоксидной расплавной матрице Т-107. По экспериментальным зависимостям $\ln Q^{-1} \sim(1 / T)$ определена температура 
стеклования полимер матрицы, которая оказалась равной $T \sim 460 \mathrm{~K}$, что в пределах погрешности совпадает с табличными данными.

По высокотемпературному участку фона внутреннего трения с учетом низкотемпературного участка фона была сделана оценка энергии миграции и энергии образования вакансиоподобных дефектов аморфной матрицы исследуемых стеклоуглепластиков, которые оказались равны $E_{m}=0.70 \pm 0.05 \mathrm{eV}$ и $E_{v}=0.66 \pm 0.05 \mathrm{eV}$.

Исследованы амплитудные зависимости внутреннего трения гибридных композитов из углеродных однонаправленных волокон и стеклянных тканей в эпоксидной расплавной матрице Т-107. Показано, что экспериментальные зависимости внутреннего трения исследованных композитов носят сугубо нелинейный характер, а наблюдаемое отставание потерь от упругой составляющей при больших амплитудах очевидно связано со спецификой структуры и упругопластических свойств композита.

Работа выполнена при поддержке Минобрнауки в рамках проектной части государственного задания (проект № 3.1867.2017/4.6).

\section{Список литературы}

[1] Каблов E.Н. // Авиационные материалы и технологии. 2015. № 1 (34). C. 3-33.

[2] Полимерные композиционные материалы: структура, свойства, технология: учеб. пособие / Под ред. А.А. Берлина. СПб.: Профессия, 2009. 560 с.

[3] Курносов А.О., Мельников Д.А., Соколов И.И. Стеклопластики конструкционного назначения для авиастроения // Труды ВИАМ: электронный научно-технический журнал. 2015. № 8.

[4] Тимошков П.Н., Хрульков А.В., Язвенко Л.Н. Композиционные материалы в автомобильной промышленности (обзор) // Труды ВИАМ: электронный научно-технический журнал. 2017. № 6.

[5] Новик А., Берри Б. Релаксационные явления в твердых телах. М.: Атомиздат, 1975. 472 с.

[6] Бартенев Г.М., Зеленев Ю.В. Физика и механика полимеров. М.: Высшая школа, 1983. $391 \mathrm{c}$.

[7] Сагомонова В.А., Кислякова В.И., Тюменева Т.Ю., Большаков В.A. Влияние состава вибропоглощающих материалов на коэффициент механических потерь // Труды ВИАМ: электронный научно-технический журнал. 2015. № 10 .

[8] Сагомонова В.А., Сытый Ю.В. Основные принципы создания вибропоглощающих материалов // Труды ВИАМ: электронный научно-технический журнал. 2013. № 11.

[9] Т-107 Институт новых углеродных материалов и технологий. 2015. URL: Электронный ресурс. Режим доступа: http://www.inumit.ru/img/file/t107.pdf

[10] Электронный ресурс. Режим доступа:

URL: http://www.fpc.com.tw/fpcwuploads/pdocument/pdocument_ 141202152439.pdf

[11] ГОСТ 19170-2001. Стекловолокно. Ткань конструкционного назначения. Технические условия. Взамен ГОСТ 19170-70; введ. 2002-01-10. Минск: Межгос. совет по стандартизации, метрологии и сертификации; М.: Изд-во стандартов, 2002. 16 с.
[12] Ovdak O.V., Kalinin Yu.E., Kudrin A.M., Karaeva O.A., Degtyarev D.Ya. // Inorganic Materials: Appl. Res. 2018. Vol. 9. N 1. P. $108-113$.

[13] Блантер М.С., Головин И.С., Головин С.А., Ильин А.А., Саррак В.И. Механическая спектроскопия металлических материалов. М.: МИА, 1994. 256 с.

[14] Мозговой А.В., Вишняков Л.Р., Синайский Б.Н., Яременко О.П., Мороз В.П. // Новые материалы и технологии в металлургии и машиностроении. 2012. № 2. С. 41-46.

[15] Золотухин И.В., Калинин Ю.Е. // ФТТ. 1995. Т. 37. Вып. 2. C. $536-545$. 